\title{
O ESPETÁCULO FUTEBOLÍSTICO E O ESTATUTO DE DEFESA DO TORCEDOR*
}

\author{
DRA. HELOISA HELENA BALDY DOS REIS \\ Doutora em educação - Unicamp \\ Professora associada, Faculdade de Educação Física - Unicamp (São Paulo - Brasil) \\ E-mail: helobaldy@yahoo.com
}

\begin{abstract}
RESUMO
Este artigo é resultante de uma pesquisa qualitativa e tem como tema o espetáculo futebolístico no Brasil e o Estatuto de Defesa do Torcedor. A pesquisa foi realizada com enfoques bibliográfico, documental e de campo, e aborda as inaplicabilidades do Estatuto de Defesa do Torcedor. Esta pesquisa conclui que aproximadamente $50 \%$ dos artigos e incisos da lei n. 10.67//03 ainda não são cumpridos, situação pela qual a Confederação Brasileira de Futebol (CBF), algumas federações afiliadas e o Poder Público são corresponsáveis.
\end{abstract}

PALAVRAS-CHAVE: Espetáculo futebolístico; legislação esportiva; Estatuto do Torcedor.

* A pesquisa não foi financiada por órgãos de fomento. Não houve conflitos de interesses para a realização do presente estudo. 
Os temas centrais deste artigo são o espetáculo futebolístico no Brasil e a lei n. 10.67//2003, mais conhecida como o Estatuto do Torcedor. $\bigcirc$ objetivo dele é analisar o cumprimento da lei pelas autoridades responsáveis. A pesquisa foi desenvolvida com metodologia qualitativa, com enfoques bibliográficos, documental e de campo. Na pesquisa de campo, foram realizadas observações sobre o cumprimento dos artigos e incisos da lei, o que nos permitiu quantificar o número de artigos e incisos cumpridos e não cumpridos.

O enfoque bibliográfico foi utilizado durante todo o período da pesquisa (que durou cinco anos), por meio dos estudos da literatura acadêmica sobre os temas: futebol, esporte espetáculo e direito esportivo. Todos esses temas foram pesquisados nas bases de dados das três universidades públicas paulistas, além dos acervos particulares; os materiais encontrados foram listados como levantamento bibliográfico e, ao longo da pesquisa, foram sendo lidos e fichados.

enfoque documental também foi utilizado ao longo de toda a pesquisa; os documentos utilizados constam das referências do artigo, e pela natureza desta pesquisa foi necessário revisitá-los várias vezes. Isso porque uma análise qualitativa cuidadosa, rigorosa e profunda demanda novas leituras e reinterpretações constantes, assim como o cotejamento e novas análises com base nos dados de campo.

Os dados de campo foram coletados em 14 visitas técnicas aos estádios de futebol (sendo duas no Brinco de Ouro da Princesa, quatro no Morumbi, duas no Pacaembu, duas no Parque Antártica, duas no Mineirão, duas no Maracanã), entre os anos de 2003 e 2008. A maioria das visitas durou cinco horas cada - com exceção das do Maracanã, que tiveram duração de duas horas cada -, totalizando 64 horas de observação na pesquisa.

Os estádios foram escolhidos seguindo o critério de representatividade e importância. Outro dado determinante na escolha é que os estados de São Paulo, Rio de Janeiro e Minas Gerais lideram o ranking de estados brasileiros com maior número de mortes em dias de jogos (REIS, 2009).

As visitas tiveram como objetivo analisar as condições dos estádios em dias de jogos (com exceção do Maracanã, onde as duas visitas técnicas ocorreram em dias sem jogos por motivo de acessibilidade e oportunidade), o que se deu por meio de observação não participante, com anotações em um diário de campo das irregularidades verificadas contra as determinações do Estatuto de Defesa do Torcedor, em relação às condições de numeração dos assentos nos estádios - foram tiradas algumas fotos do Parque Antártica, do Brinco de Ouro da Princesa e do 
Morumbi (critério de acessibilidade) - e às condições das instalações sanitárias e sua manutenção - no setor mais popular dos estádios frequentado pelas torcidas organizadas'.

A pesquisa contou também com três reuniões com o promotor público de São Paulo, dr. Paulo Castilho (membro do Juizado Especial Criminal, Jecrim - SP); com a delegada da polícia civil, dra. Margarette Barreto (delegada da Delegacia de Crimes Raciais e Delitos de Intolerância - Degradi -, responsável pela delegacia móvel em dias de clássicos); com os comandantes do policiamento militar (nos dias dos jogos); e com o ex-comandante de policiamento em estádios de São Paulo e atual diretor de segurança da Federação Paulista de Futebol, tenente-coronel Marcos Cabral Marinho; a fim de obter informações sobre o funcionamento do Jecrim em São Paulo, e sobre o planejamento da segurança em dias de jogos na capital paulista².

Além dos procedimentos descritos, foram realizadas pesquisas semanais nos sites da Confederação Brasileira de Futebol (CBF) e da Federação Paulista de Futebol (FPF), com o intuito de investigar novas normas para a organização do espetáculo futebolístico, ou para consultar borderôs de jogos, locais de vendas de ingressos, relação de pessoas impedidas de entrar nos estádios etc. - conforme determinam os capítulos II e $V$ do Estatuto de Defesa do Torcedor.

A pesquisa beneficiou-se também das trocas com a sociedade civil (jornalistas, cronistas esportivos, operadores do direito, telespectadores de mesas esportivas, coordenador executivo da Consegue ${ }^{3}$ ) e com colegas acadêmicos, principalmente da área de direito esportivo, tanto do Brasil como da Espanha, nas várias ocasiões em que fui convidada para apresentar e debater o tema, seja em eventos cientíicos, seja em governamentais, ou ainda em programas televisivos ou radiofônicos.

O presente artigo organiza-se da seguinte forma: a introdução teve por finalidade apresentar o tema, o objetivo e o método da pesquisa. A seguir, no segundo item, será desenvolvida a análise dos dados dos enfoques de campo e documental, sempre referenciados nos estudos bibliográficos e documentais realizados. E, no terceiro item, será apresentada uma breve síntese com as considerações finais do artigo e as sugestões oriundas da pesquisa.

I. Com exceção do Mineirão e do Maracanã, nos quais foi observado o setor das cadeiras superiores.

2. As reuniões com os três primeiros foram realizadas no estádio do Morumbi em dias de funcionamento do Jecrim, nos anos de 2006 e 2007. Já com o último citado, a reunião foi realizada na sede da Federação Paulista de Futebol, no ano de 2007.

3. Comissão Nacional de Prevenção da Violência para a Segurança nos Espetáculos Esportivos, mais conhecida como Comissão Paz no Esporte. 


\section{AS REFERÊNCIAS LEGISLATIVAS BRASILEIRAS E AS SUAS INAPLICABILIDADES NO FUTEBOL ESPETÁCULO}

Os desmandos do futebol brasileiro, evidentes no excesso de poder da CBF e das federações estaduais - principalmente na organização de seus respectivos campeonatos, com o predomínio de descompromisso com o público, verificado pela falta de divulgação dos regulamentos das competições, constantes mudanças de regras de acesso e decesso nos principais campeonatos até 2003 -, levaram o Congresso Nacional, após o encerramento da Comissão Parlamentar de Inquérito (CPI) CBF-Nike sobre o futebol (REBELO; TORRES, $200 \mathrm{I}$ ), a tramitar e aprovar o Estatuto de Defesa do Torcedor (lei n. 10.67I, de maio de 2003), também conhecido como a "lei de moralização do futebol".

Sobre a situação do futebol no país, Rebelo e Torres (200 I, p. 19 e 24) afirmam que:

No Brasil, como a atividade ainda é administrada de forma amadorística e os negócios feitos em grande parte na informalidade, o resultado tem sido uma elevação do grau de corrupção [...].

Na medida em que as denúncias foram sendo formuladas e foram amplamente divulgadas pela televisão, rádio e jornais, o grande público pôde conhecer o grau da degradação em que se encontram a CBF e a administração do futebol no país.

O Estatuto de Defesa do Torcedor, sancionado pelo presidente da República, estabelece normas de proteção e defesa do torcedor. Em seu artigo $2^{\circ}$, define que "Torcedor é toda pessoa que aprecie, apoie ou se associe a qualquer entidade de prática desportiva do País e acompanhe a prática de determinada modalidade esportiva" (BRASIL, 2003).

No artigo $3^{\circ}$, a lei equipara a entidade responsável pela organização da competição e a detentora do mando de jogo a fornecedores, nos termos da lei n. 8.078, de II de setembro de 1990, popularmente conhecida como "Código do Consumidor".

Esse ato normativo teve como propósito atribuir a alguma instituição a defesa do torcedor. Porém a difusa atribuição verificada no artigo 4I, que diz que

A União, os Estados, O Distrito Federal e os Municípios promoverão a defesa do torcedor, e, com a finalidade de fiscalizar o cumprimento do disposto nesta Lei, poderão:

I - constituir órgão especializado de defesa do torcedor; ou

II - atribuir a promoção e defesa do torcedor aos órgãos de defesa do consumidor (BRASIL, 2003, art. 4I, II). 
dificultou sua fiscalização. Passaram-se vários anos até que algum órgão público de São Paulo assumisse a responsabilidade de supervisionar o setor, assim como os torcedores soubessem onde realizar suas reclamações ${ }^{4}$ quando se sentissem lesados. Apenas no final de 2005, portanto dois anos e meio após a entrada em vigor da lei, o Procon de São Paulo registrou a primeira queixa de torcedores.

Ostatuto é aplicável a todas as modalidades esportivas geridas pelas entidades de administração do esporte bem como pelas ligas de que trata o artigo 20 da lei n. 9.615, de 24 de março de 1998 (BrasIL, 2003, art. 5).

Apesar dos limites da lei e de sua implementação apresentados neste artigo, a sanção do Estatuto de Defesa do Torcedor foi de grande importância para a sociedade brasileira, e tornou-se um marco para o exercício da cidadania no Brasil, já que até maio de 2003 os promotores de eventos esportivos não tinham obrigações claras com o grande público assistente dos espetáculos e, em contrapartida, o espectador não tinha a quem recorrer quando se sentia maltratado e desrespeitado em atividades de lazer esportivo. O reconhecimento da importância da lei pelos torcedores foi comprovado na pesquisa realizada por Silva et al. (2007b, p. 3 e 5), em Belo Horizonte, que constatou que "88,33\% dos torcedores de futebol" afirmam que o Estatuto de Defesa do Torcedor "é um documento importante". Mesmo assim, apesar desse alto nível de reconhecimento, os autores encontraram um "baixo conhecimento acerca da existência e do conteúdo do EDT ${ }^{5 "}$; segundo eles, 66,7\% dos torcedores de futebol entrevistados afirmaram não conhecer o Estatuto e, entre os que declararam conhecê-lo, "muitos possuíam um conhecimento superficial", sabendo apenas da sua existência. Os dados mencionados evidenciam a natureza contraditória dos depoimentos colhidos pelos entrevistadores.

O baixo nível de conhecimento da existência do Estatuto e o desconhecimento do seu teor estão na minha avaliação (com base nas pesquisas de campo e documental) relacionados à ausência de um programa de divulgação da lei por parte dos governos e das entidades promotoras de espetáculos esportivos ${ }^{6}$. O tema ficou restrito à mídia esportiva, que divulgou intensamente a lei, mas limitou o debate sobre ela a alguns programas esportivos (muitos de TVs pagas) - e, na maioria das

4. No estado de São Paulo, um dos pioneiros nesse tipo de queixa, somente no ano de 2005 é que foi registrada a primeira reclamação no Procon. Com isso, o órgão precisou agilizar a criação de uma Câmara Técnica do Desporto para dar andamento à reclamação. Disponível em: <http:// www.procon.sp.gov.br/texto.asp?id=|848>. Acesso em: I6 out. 2006.

5. Os autores criaram a sigla EDT para se referirem ao Estatuto de Defesa do Torcedor.

6. Sugiro que os clubes mandantes tenham disponível para o espectador a lei impressa em papel, da mesma forma como ocorre com o Código do Consumidor. Os estabelecimentos comerciais são obrigados a exibir cartazes que deixem à disposição do cliente o texto da lei. 
vezes, o assunto foi tratado com muita superficialidade, desconfiança e dúvida a respeito do seu efetivo cumprimento no Brasil.

Análise esta que converge com a de Rigo et al. (apud SILVA et al., 2007b, p. 3), na qual se afirma que: "Ao tratar do EDT a mídia apresenta-o de maneira superficial em meio a noticiários televisivos, artigos de jornais e revistas apenas citando-o, sem, contudo, evidenciar de que forma ele interferiria no assunto tratado em tais notícias".

$\mathrm{O}$ inciso $\mathrm{VI}$ do artigo $5^{\circ}$ da lei n. 10.67।/03 diz que as entidades de administração do esporte bem como as ligas irão publicar na internet "a relação dos nomes dos torcedores impedidos de comparecer ao local do evento desportivo" (BRASIL, 2003). Porém a única publicação feita até o momento foi no final do primeiro semestre de 2008, pela CBF.

○ capítulo IV também não é cumprido; em seu artigo 13 aparece que "O torcedor tem direito à segurança nos locais onde são realizados os eventos esportivos antes, durante e após a realização das partidas" (BRASIL, 2003). As observações feitas nesta pesquisa em campo constataram que existem várias dificuldades para o cumprimento dessa determinação, desde aquelas de ordem estrutural até as de competências específicas, como, por exemplo, a necessidade de um preparo mais aprimorado do corpo de segurança que trabalha nos dias de jogos. A falta de estrutura dos recintos esportivos e de sincronia entre todas as instituições públicas responsáveis pela vigilância nos estádios e suas imediações (vigilância sanitária, fiscalização de ruas - ambulantes -, guarda municipal etc.) é outro fator complicador para o cumprimento e a eficácia dessa lei.

A segurança durante a realização do espetáculo futebolístico (entre o início e o término do jogo) de certa maneira está assegurada, o que se dá principalmente pela existência do circuito fechado de TV e pela presença ostensiva da Polícia Militar nas arquibancadas ${ }^{8}$. Sobre o assunto, realizei estudos detalhados (REIS, 2003, 2006), e esta pesquisa corrobora essas conclusões, que apontam para o descumprimento do capítulo IV quase que integralmente.

Sobre a sensação do torcedor com a segurança, Silva et al. (2007b) entrevistaram torcedores de futebol em Belo Horizonte, e concluíram que "29, $16 \%$ dos torcedores consideraram baixo o nível de segurança na 'chegada ao estádio'”, e "relataram que a segurança 'varia com o jogo'", "quanto mais cedo chegar, melhor"; já 55,83\% se sentiam seguros ao ir para o estádio, e 83,33\% se sentiam seguros dentro do estádio; foi notado por Silva et al. (2007a, p. 4-5) "que a segurança dos torcedores está relacionada ao lugar, ou setor, que ocupam no estádio e a proximi-

7. Para maior detalhamento dessas condições, ver Reis (2006).

8. Sobre uma visão crítica da presença dos policiais, ver Reis (2006). 
dade, ou não, de torcidas organizadas". E, "em relação à saída do estádio, 48,33\% dos torcedores consideraram baixa a segurança".

Ainda a respeito deste capítulo - Sobre a segurança -, é atribuída ao Poder Público a responsabilidade pela segurança dos torcedores dentro e fora das praças esportivas (art. 14, item I). No entanto, as observações feitas durante a realização dos jogos confirmaram o verificado em Reis (2006): a Polícia Militar tem mantido um enorme contingente dentro dos estádios durante o jogo e praticamente ignorado o que acontece no seu entorno.

Sobre a segurança após o jogo, observei em campo que o número de policiais diminuiu bastante, pois imediatamente após o término da partida os soldados foram levados para o Batalhão de Choque em caminhões da corporação, quando deveriam ser deslocados, na minha opinião, para dar apoio aos espectadores nos trajetos entre o estádio e os transportes.

Os torcedores entrevistados por Silva et al. (2007b) também tiveram essa mesma percepção; segundo eles, os policiais se "preocupam muito dentro do estádio e esquecem lá fora" (torcedor organizado, 25 anos); "lá fora é fria, salve-se quem puder" (torcedor, 22 anos). Silva et al. (2007b, p. 4) puderam verificar também que, "imediatamente após o término da partida, grande parte do contingente policial destacado para o jogo deixa o estádio, o que diminui drasticamente a segurança ou pelo menos a percepção/sensação de segurança pelo torcedor".

Com os conhecimentos adquiridos em 14 anos de pesquisa sobre o tema da segurança em dias de jogos, observo que os organizadores e os agentes de segurança não fazem um planejamento adequado para este tipo de espetáculo. Isso quer dizer que o contingente de policiais militares não deve retornar majoritariamente ao quartel imediatamente após o término do jogo. Eles deveriam ser estrategicamente realocados para as vias públicas, no entorno do estádio, e sobretudo para as principais vias de evasão dos torcedores. Porém, para que isso seja possível, são necessárias mudanças na organização do policiamento, pois essa ação acarretaria atualmente interferência nas ações de outro destacamento da PM (policiamento de área). Isso comprova mais uma vez a necessidade de diálogo entre as coordenações de segurança pública em dias de jogos de futebol nas grandes cidades ${ }^{9}$. Ou melhor, é necessária uma mudança na operação do policiamento em dias de jogos. Recomenda-se que o Batalhão de Choque em São Paulo volte a ser o responsável pelo policiamento interno e externo do estádio.

O planejamento de segurança deve ser elaborado tendo como parâmetro o tipo de jogo que irá realizar-se, ou seja, avaliando qual o seu risco previsível. Em Reis

9. Essa necessidade também foi observada por Klein (2006). 
(2006), foi abordado o tema do risco em jogos de futebol, e sugeriu-se a classificação desses jogos, no Brasil, com base nas políticas de prevenção da violência dos países europeus - os quais conseguiram controlar e diminuir os índices de violência física e vandalismo em dias de jogos de futebol -, que categorizam os jogos como de baixo risco, médio risco e alto risco. Para fazer essa classificação, esses países levam em conta o histórico dos jogos anteriores entre as equipes (confrontos e rivalidades), a preparação do jogo (principalmente a expectativa de público) e a classificação das equipes no campeonato (importância do jogo). Todos esses fatores analisados conjuntamente fornecerão o grau de risco do jogo, e o planejamento de segurança das polícias deve ser elaborado ou alterado de acordo com esse nível.

No Brasil, o planejamento de segurança do jogo ${ }^{10}$ está previsto no artigo 17 do estatuto, que diz que:

É direito do torcedor a implementação de planos de ação referentes a segurança, transporte e contingências que possam ocorrer durante a realização de eventos esportivos. [...]

$\S 2^{\circ}$ Planos de ação especiais poderão ser apresentados em relação a eventos esportivos com excepcional expectativa de público (BrASIL, 2003).

Porém, durante as pesquisas de campo e documental, esses planos não foram encontrados ou mesmo informados por seu comandante. $O$ sigilo ou a inexistência de um plano de ação também foram observados por Klein (2006) em sua análise da situação da segurança nos espetáculos futebolísticos, realizada a serviço do Ministério do Esporte.

A presente pesquisa observou várias situações pelas quais é permitido afirmar que o Estado promove uma má gerência dos seus recursos humanos e financeiros na segurança pública em dias de jogos. Uma dessas situações, além da exposta anteriormente, é, por exemplo, a atuação da Polícia Militar em eventos futebolísticos. Prevê-se nos estudos sobre o tema que o cálculo do número de agentes de segurança (policiais) em um espetáculo futebolístico seja feito com base em três parâmetros: a expectativa de público para o evento - averiguada pela venda antecipada dos ingressos para o jogo e pelo seu histórico; o risco potencial calculado para o jogo; e o histórico de enfrentamento entre as equipes participantes.

Sendo assim, posso exemplificar duas situações. Uma, no clássico espanhol em que todos os fatores supracitados foram levados em consideração -, entre Real Madrid e Barcelona, em 1999, quando a polícia espanhola destacou 269 policiais para o jogo que teve a presença de 80 mil espectadores, no Estádio do Barcelona.

10. Em São Paulo, a lei n. 5। 45, de 30 de maio de 1986: Disciplina o comparecimento de policiais em espetáculos artísticos, culturais, circenses ou esportivos. 
E outra, no interior de São Paulo, no mesmo ano, em um clássico ("derby") entre Guarani e Ponte Preta no Estádio Brinco de Ouro da Princesa (do Guarani), em que foram destacados aproximadamente 700 policiais militares para trabalhar em um jogo com público inferior a 40 mil espectadores. O grande número de policiais poderia indicar maior segurança, porém não foi o que ocorreu, porque no primeiro exemplo não houve registros de incidentes de violência e vandalismo relacionados ao jogo, e no segundo, sim. $\bigcirc$ aumento no número de policiais não leva necessariamente ao aumento da segurança. Para os especialistas em prevenção da violência em espetáculos esportivos, um cálculo excessivo de policiais demonstra erro no planejamento da ação, e não aumento da segurança, como os leigos poderiam imaginar.

Esta pesquisa, assim como a de Escher (2004) e a de Silva et al. (2007b), comprova a necessidade de mudanças na organização do espetáculo, conforme já sugerido em Reis (2006).

As observações realizadas nesta pesquisa constataram que não há um esquema especial de transporte público para os estádios em dias de jogos, e tampouco existem estacionamentos suficientes para os veículos que são deslocados para as imediações dos estádios ". Outro problema enfrentado pelos torcedores em jogos em estádio de futebol nas grandes cidades é a impossibilidade de se livrar das constantes coações exercidas pelos "flanelinhas" ao estacionarem seus veículos nas vias públicas no entorno dos estádios, sendo este mais um dado que comprova o descumprimento do capítulo VI da lei, que trata especificamente do transporte, e do seu artigo 27, que obriga os organizadores de eventos esportivos a providenciar estacionamentos, diretamente ou mediante convênio (BraSIL, 2003) ${ }^{12}$.

Ainda sobre a segurança, os torcedores de Minas Gerais declararam a Silva et al. (2007b) que "a segurança deveria começar pelo transporte e pelo estacionamento; resolvendo esses dois problemas, inibe-se a violência em outros locais".

A presente pesquisa observou também que a venda de alimentos e bebidas nos estádios é limitada; na maioria dos casos, vende-se apenas um tipo de produto para comer e um para beber, com preços ${ }^{13}$ muito acima dos praticados em bares

1 I. Esses dados foram obtidos em pesquisas nos sites dos clubes participantes dos jogos nos dias que os antecederam na capital paulista. Quando os jogos eram realizados na cidade de São Paulo, foi feita também pesquisa no site da Secretaria Municipal de Transportes. Em La Corte (2007), encontram-se dados semelhantes.

12. Essa observação foi realizada em períodos de uma a duas horas antes do início dos jogos, nas imediações dos estádios visitados, e teve o objetivo de verificar as ações e o comportamento dos flanelinhas e dos motoristas abordados.

13. Verificados em 2008 foram: copo de água mineral, $R \$ 2,00$; sorvetes e salgadinhos em pacotes pequenos, $R \$ 4,00$; refrigerantes ou cerveja sem álcool, $R \$ 3,00$ - seguramente alguns itens apresentavam sobrepreços de $75 \%$ a $100 \%$. 
e restaurantes, e com condições de higiene duvidosas, já que os requisitos exigidos pela vigilância sanitária (azulejos em todas as paredes, funcionários com luvas, toucas etc.) para este tipo de estabelecimento não estão presentes. O número de balconistas também não é suficiente para a demanda no intervalo dos jogos, o que causa tumulto e gera muitas vezes situações de brigas e discussões entre os consumidores. Esses dados relativos à alimentação e higiene são similares aos encontrados por Escher (2004) em sua pesquisa no Brinco de Ouro da Princesa em Campinas, assim como os encontrados por Silva et al. (2007b) em Minas Gerais.

A obrigatoriedade de boas condições de higiene no local de venda dos alimentos e nos equipamentos está contemplada no capítulo VII da lei, que, em seu artigo 28, diz que "O torcedor partícipe tem direito à higiene e à qualidade das instalações físicas dos estádios e dos produtos alimentícios vendidos no local." Portanto, esta pesquisa e as dos colegas citados comprovam também o descumprimento desse capítulo da lei do Estatuto de Defesa do Torcedor.

O artigo 29 diz que "É direito do torcedor partícipe que os estádios possuam sanitários em número compatível com sua capacidade de público, em plenas condições de limpeza e funcionamento" (BrasIL, 2003). Constatei, entretanto, as péssimas condições dos sanitários nos estádios observados, tanto no que tange às condições de higiene quanto ao número de unidades sanitárias por setor. Cada unidade sanitária tem o número de vasos sanitários e mictórios infradimensionado para a grande demanda de usuários. Todos os sanitários destinados a homens e muIheres foram inspecionados antes do início dos jogos, sendo que os femininos foram visitados antes e durante os jogos (critério de acessibilidade). Todos apresentavam mau cheiro, até mesmo antes do início das partidas; vários apresentavam poças de água no chão, nenhum continha cestos de lixo e tampouco informação se os papéis higiênicos poderiam ser atirados nas latrinas, o que ocasionava o acúmulo de uma grande quantidade de papéis usados no chão dos banheiros femininos.

O descumprimento desse artigo foi observado tanto por Silva et al. (2007b) como por Escher (2004, p. 35); este último constatou que, no estádio de Campinas,

Todos os sanitários destinados aos espectadores masculinos foram observados e nenhum demonstrou condições satisfatórias de uso. [...] Além de que, as paredes estavam todas pichadas, os urinários estavam em péssimas condições de higiene e nenhum vestígio de papel higiênico foi encontrado durante os jogos, o que contribuía para o péssimo cheiro do local.

Um dos limites do Estatuto do Torcedor foi não determinar o número de sanitários e vasos por unidade sanitária, compatível com sua capacidade de público. Por isso, utilizei como parâmetro para a análise as normas europeias. Estas determinam um banheiro masculino com dois vasos sanitários, seis mictórios e duas 
pias por unidade sanitária para cada mil espectadores em potencial (considerando a capacidade do estádio, e não a previsão de homens frequentadores). E, para as unidades femininas, um banheiro com três vasos sanitários e uma pia por unidade sanitária. $\bigcirc$ estádio em que encontrei melhores condições (levando em consideração instalações e limpeza) foi o do Morumbi, em São Paulo, que tem capacidade para 72.039 espectadores; no setor reservado para os torcedores organizados (arquibancada amarela), que tem capacidade para 10 mil espectadores, havia três sanitários masculinos, sendo cada um deles equipado com dois mictórios e seis vasos sanitários, as pias com quatro torneiras cada uma ficavam externas ao sanitário, e eram utilizadas também como bebedouros. Para mulheres, havia apenas um banheiro, equipado com nove vasos sanitários e quatro pias. Considerando a legislação europeia, a capacidade de público para o setor, dimensionado com base nas instalações sanitárias, seria de aproximadamente cinco mil espectadores em potencial.

A venda dos ingressos é tema do capítulo $\vee$ do estatuto e está entre as normas menos cumpridas pelos organizadores dos espetáculos futebolísticos, conjuntamente com os capítulos VI - Do transporte - e VII - Da alimentação e higiene. Nos dias que antecedem os jogos, há uma aglomeração muito grande de pessoas para a compra dos ingressos nas bilheterias dos estádios ${ }^{14}$. Há um pequeno número de ingressos para estudantes ${ }^{15}$. $\bigcirc$ local de compra de ingressos de estudantes é em guichê diferente do dos outros tipos de ingressos, o que dificulta que um único membro da família compre ingressos para estudantes e não estudantes. A ordenação das filas é feita com muita truculência pelos agentes de segurança pública. Não há informações sobre outros locais de venda. $\bigcirc$ atendimento dos vendedores dos guichês é descortês. Quer dizer, no primeiro contato do espectador com a organização do espetáculo, a sensação é muito ruim pelos acontecimentos mencionados e o atendimento é um desestímulo a esse tipo de lazer.

Estes últimos dados são convergentes com os encontrados por Silva et al. (2007b, p. 6):

[...] a falta de organização na venda de ingressos, em especial no dia dos jogos, é um problema que também atinge o futebol. Filas enormes que se transformam em grandes aglomerações no momento da chegada aos guichês, ausência de tabela com valores dos ingressos, despreparo dos funcionários responsáveis pela venda são problemas que pudemos observar em nossas incursões a campo.

\footnotetext{
14. Verificado nas várias tentativas que meus alunos (às vezes, acompanhados por mim) fizeram de comprar ingressos para estudantes no primeiro dia de venda, assim como em outras ocasiões na véspera dos jogos. Verificado também por La Corte (2007).

15. Informaçã̃o coletada nos programas televisivos na semana do jogo e, em alguns casos, na observação direta da pesquisadora na véspera do jogo.
} 
Em todas as visitas técnicas aos estádios pesquisados, pude observar até meados de 2007 (antes da visita dos membros da Federação Internacional de Futebol - Fifa - aos estádios paulistas) que os preços dos ingressos e a especificação da localização dos setores dentro dos estádios não estavam afixados nas imediações das bilheterias, como designa a lei ${ }^{16}$. As filas para a compra dos ingressos na semana que antecede o jogo são constantes até hoje, assim como o rápido término dos ingressos para estudantes e/ou para os setores mais baratos, sem maiores comprovações de como em tão pouco tempo foram vendidos tantos ingressos. Sobre essa questão, durante a pesquisa, um torcedor carioca deu um depoimento curioso que foi publicado por Juca Kfouri. O torcedor fluminense, que tentou comprar um ingresso de estudante para assistir ao seu time predileto, relatou que:

Os ingressos acabaram em quatro horas, segundo informações oficiais, em todos os postos de venda, mas se considerarmos os cinco postos e os 60.000 ingressos, seriam 12.000 ingressos por posto, que divididos por 240 minutos (4 horas) seria como se os caixas dos 5 postos vendessem 50 ingressos por minuto, e como existe o limite de 2 ingressos por pessoa, seriam 25 pessoas por minuto, quase uma pessoa a cada 2 segundos... (VASCONCELlos, 2008).

A lei ora em apreço determina, em seu capítulo $V$, que a venda dos ingressos deve ser ágil e a informação sobre ela, ampla. Para a averiguação do cumprimento desse capítulo, que inclui a obrigatoriedade de cinco pontos de vendas de ingressos, esta pesquisa se utilizou, além das técnicas mencionadas, de pesquisa nos sites dos organizadores do espetáculo futebolístico (CBF, FPF e clubes participantes dos jogos), e pôde constatar que esses pontos não eram divulgados. Inúmeras matérias televisivas e jornalísticas denunciaram no período desta pesquisa o descumprimento dessa obrigatoriedade.

Ainda sobre os ingressos, o artigo 22 do estatuto diz que:

São direitos do torcedor partícipe:

I - que todos os ingressos emitidos sejam numerados; e

II - ocupar o local correspondente ao número constante no ingresso (BRASIL, 2003).

Sobre esses incisos, pode-se afirmar que, logo após a entrada em vigor do Estatuto de Defesa do Torcedor, as arquibancadas dos estádios paulistas foram pintadas com demarcações de 35 a $40 \mathrm{~cm}$ de largura (inferiores à recomendação internacional, que é de $50 \mathrm{~cm}$ ) e com numeração progressiva. No entanto, as obrigações previstas no artigo 22, supracitadas, não foram cumpridas até hoje

16. Isso passou a ser afixado no Estádio do Morumbi após a visita dos observadores da Fifa para ver as condições do estádio para sediar o Mundial de 2014. 
pelos organizadores, pois a numeração existente nos ingressos não corresponde à existente no interior dos recintos esportivos. Essas anomalias foram registradas na pesquisa por meio do diário de campo e por fotografias.

Outra iniciativa importante no âmbito da promoção de espetáculos futebolísticos foi a criação dos Juizados Especiais Criminais (Jecrims), que surgiram após a promulgação do Estatuto de Defesa do Torcedor. Eles foram criados, inicialmente, no Rio de Janeiro e em Belo Horizonte. Já em São Paulo, foi preciso uma articulação do secretário executivo da Comissão Nacional de Prevenção da Violência para a Segurança nos Espetáculos Esportivos (Consegue), no ano de 2006, para que o Judiciário designasse um juiz para o início do funcionamento do primeiro juizado instalado no estádio do Morumbi ${ }^{17}$. A implantação dos Jecrims gerou uma sensação do fim da impunidade entre o público frequentador, e fez diminuir os incidentes de agressões físicas dentro dos estádios paulistas.

Os Jecrims do Rio de Janeiro e de Belo Horizonte têm surtido efeitos muito positivos; os de São Paulo ainda necessitam de maior articulação entre os comandantes da segurança pública paulista e os operadores de direito que atuam nos juizados.

artigo 39 prevê que:

O torcedor que promover tumulto, praticar ou incitar a violência, ou invadir local restrito aos competidores ficará impedido de comparecer às proximidades, bem como a qualquer local em que se realize evento esportivo, pelo prazo de três meses a um ano, de acordo com a gravidade da conduta, sem prejuízo das demais sanções cabíveis.

$\S 1^{\circ}$ Incorrerá nas mesmas penas o torcedor que promover tumulto, praticar ou incitar a violência num raio de cinco mil metros ao redor do local de realização do evento esportivo.

$\S 2^{\circ} \mathrm{A}$ verificação do mau torcedor deverá ser feita pela sua conduta no evento esportivo ou por Boletins de Ocorrências Policiais lavrados.

$\S 3^{\circ} \mathrm{A}$ apenação se dará por sentença dos juizados especiais criminais e deverá ser provocada pelo Ministério Público, pela polícia judiciária, por qualquer autoridade, pelo mando do evento esportivo ou por qualquer torcedor partícipe, mediante representação (BRASIL, 2003).

Verificou-se que o seu cumprimento ficou restrito aos dias de clássicos e somente depois de três anos da promulgação da lei. Apesar desse artigo, nas três vezes em que observei o funcionamento da delegacia móvel e do próprio Jecrim,

17. Até julho de 2008, os juizados funcionaram apenas nos clássicos realizados no Morumbi e no Parque Antártica. 
notei que, até final de 2007, não foram todas as ocorrências e detenções realizadas pela PM que foram registradas em Boletins de Ocorrências na Polícia Civil (delegacia móvel). A própria Polícia Militar muitas vezes decidiu encaminhar os detidos para a delegacia mais próxima ao estádio em vez de registrar a ocorrência na unidade móvel instalada para esse fim dentro do estádio ${ }^{18}$. Esse panorama foi modificado a partir de 2008, com maior articulação e compromisso dos setores envolvidos.

Esta pesquisa pôde comprovar, nas visitas técnicas realizadas, por meio de relato do promotor responsável e da delegada de plantão, que não tem existido, de fato, um controle para eventual impedimento da entrada dos indivíduos já punidos nos estádios paulistas, o que demonstra a necessidade de um trabalho mais articulado entre todos os agentes envolvidos na organização do espetáculo esportivo e na sua segurança. Foi possível também avaliar pelas pesquisas nos sites da CBF e da FPF que neles não constavam mais do que dois indivíduos impedidos de entrar nos estádios brasileiros durante a pesquisa. Tal fato levanta a seguinte questão: Foram apenas dois os causadores de tumultos ou os incitadores de violência em dias de jogos? Houve apenas dois julgamentos com tal punição pelos Jecrims de todo o país? Ou as penas são tão brandas que não são informadas a tempo para as entidades organizadoras dos espetáculos futebolísticos? Para responder a essas questões, seria preciso aprofundar a pesquisa com entrevistas dos juízes dos Jecrims. Porém, o que se observou nesta pesquisa é que está havendo de fato algum descompasso entre o ato de deter e a divulgação das penas pela instituição responsável.

É necessário preparo mais adequado dos operadores de segurança; no meu modo de avaliar, o ideal seria a criação de um corpo de segurança pública especializado em espetáculos esportivos, porque muitas vezes os próprios agentes de segurança são os geradores de conflitos nos estádios e nas suas imediações (REIS, 1998). O recente depoimento do torcedor em um blog ajuda a exemplificar a urgência já denunciada em pesquisas anteriores (REIS, 1998, 2006; KLEIN, 2006):

A situação de meu primo foi ainda pior, pois quase foi atingido por policiais, se é que se pode chamar de protetor da ordem quem bate indiscriminadamente em mulheres, idosos e crianças; e ele, que estava na fila desde às 5 da manhã, também saiu sem ingressos (VASCONCELlos, 2008).

Na tragédia no Estádio da Fonte Nova, em Salvador, em novembro de 2007, onde morreram oito pessoas, vítimas do desmoronamento de uma parte da

18. Tal procedimento contribui para aumentar a animosidade entre as diferentes corporações que trabalham no espetáculo futebolístico. 
arquibancada, ficou evidente que o artigo 23 do estatuto também não vinha sendo cumprido integralmente. Nele consta que:

A entidade responsável pela organização da competição apresentará ao Ministério Público dos Estados e do Distrito Federal, previamente à sua realização, os laudos técnicos expedidos pelos órgãos e autoridades competentes pela vistoria das condições de segurança dos estádios a serem utilizados na competição.

$\S 1{ }^{\circ}$ Os laudos atestarão a real capacidade de público dos estádios, bem como suas condições de segurança (BRASIL, 2003).

No entanto, paradoxalmente, foi apenas em 16 de março de 2009 que o presidente Lula decretou a regulamentação do artigo 23 da lei n. 10.67।/03, "que dispõe sobre o controle das condições de segurança dos estádios desportivos" (BRASIL, 2009). Em 5 e 6 de novembro de 2009, o Ministério do Esporte, o Conselho Nacional de Justiça (CNJ) e a CBF promoveram em Brasília o seminário "Estádios, segurança e condições de uso" 19 para divulgar o decreto n. 6.795/09 e a portaria n. 124 do Ministério do Esporte que "estabelece os requisitos mínimos a serem contemplados nos laudos técnicos previstos no Decreto n. 6.795/2009". A sucessão de medidas normativas comprova a morosidade do poder público em fazer cumprir as leis neste país. Espera-se, quando uma lei é promulgada, que os responsáveis por sua elaboração desencadeiem as ações e medidas necessárias para a sua regulamentação, mas não foi o que ocorreu com o Estatuto do Torcedor. Passaram-se seis anos entre a sua aprovação e a regulamentação do seu artigo 23.

No entanto, em São Paulo, a situação está melhorando; em seu depoimento, o diretor de segurança da Federação Paulista de Futebol relatou que, no primeiro semestre de $2008,90 \%$ dos estádios paulistas conseguiram cumprir essa determinação, apresentando o alvará do Corpo de Bombeiros ${ }^{20}$, o qual atesta suas condições de segurança. Segundo ele, antes o índice de estádios que possuíam alvarás de funcionamento era irrisório.

O artigo 25 do Estatuto de Defesa do Torcedor foi um dos artigos mais polêmicos na ocasião da aprovação da lei; nele aparece que "O controle e a fiscalização do acesso do público ao estádio com capacidade para mais de vinte mil pessoas

19. Os seminaristas convidados foram os promotores de justiça de todo o Brasil, os administradores de estádios da $I^{a}$ e $2^{a}$ divisão do futebol nacional e os presidentes de clubes de futebol participantes dessas mesmas divisões. Na ocasião, fui convidada para proferir a palestra "Futebol e violência".

20. Apesar de o laudo do Corpo de Bombeiros atender a exigência atual, La Corte (2007) apresenta em sua pesquisa que o Pacaembu, o Morumbi, o Mineirão e o Maracanã (estádios pesquisados por ele) não apresentam condições de uso, segurança e conforto compatíveis com as normas europeias. 
deverá contar com meio de monitoramento por imagem das catracas" (BRASIL, 2003). Esta pesquisa constatou que, até julho de 2008, nem todos os estádios visitados cumpriam esse requisito. No entanto, desde maio de 2003, a simples divulgação dessa medida pela mídia fez com que os espectadores mudassem seus comportamentos e deixassem de se agredir fisicamente no interior dos estádios. Hoje esse tipo de incidente é raríssimo. Entretanto, houve um aumento de confrontos físicos nas imediações dos estádios e em suas vias de acesso (trajetos).

A FPF, percebendo a morosidade do Ministério do Esporte em relação aos trabalhos da Consegue, decidiu por meio da resolução n. 37/06 nomear o tenentecoronel Marcos Cabral Marinho de Moura21 para o cargo de diretor de segurança e prevenção de violência da FPF. Essa resolução, juntamente com a resolução n. 35/06, têm permitido a implementação das sugestões apresentadas no Relatório final da Fase I dos trabalhos realizados pela Consegue nos jogos de responsabilidade da entidade (Federação Paulista de Futebol, 2008a e 2008b).

\section{CONSIDERAÇÕES FINAIS}

No Brasil, a lei n. 10.67I, de 15 de maio de 2003 - que dispõe sobre o Estatuto de Defesa do Torcedor e dá outras providências -, foi um grande avanço para a elaboração de normas específicas e para a atribuição de responsabilidades na organização de eventos esportivos. Sobre essa lei, posso afirmar que o avanço foi ela própria e a determinação de algumas responsabilidades, ainda que difusas, que foram abordadas ao longo deste texto. Já os limites dessa lei, em síntese, são:

- a limitação da capacidade de público e do tipo de competição - apenas para estádios acima de 20 mil espectadores em potencial e para competições esportivas profissionais;

- a não qualificação das punições;

- a imprecisão nas responsabilidades;

- a ausência de normatização quanto à numeração e ao tipo de assento, assim como quanto à divisão dos setores das arenas esportivas;

- a falta de acompanhamento das ações legais necessárias para a entrada em vigor de todos os artigos da lei, como, por exemplo, o que ocorreu com o artigo 23 do Estatuto de Defesa do Torcedor.

21. Um dos maiores especialistas do Brasil em segurança de espetáculos esportivos. 
Pude constatar nesta pesquisa que aproximadamente metade dos artigos e incisos do Estatuto de Defesa do Torcedor ainda não são cumpridos ${ }^{22}$, fato que preocupa e aponta, para a sociedade civil, para as instituições esportivas e para o Poder Público, a necessidade de se dar maior atenção ao cumprimento das leis brasileiras.

Sendo o espetáculo esportivo um evento de massa, a obrigação dos organizadores de eventos esportivos e do Estado torna-se inadiável, sob o risco da perda de muitas vidas além das já desperdiçadas - aproximadamente 25 mortes ocorridas em São Paulo, nos últimos dez anos, e oito ocorridas em Salvador no episódio do Estádio da Fonte Nova ${ }^{23}$.

A criação dos Jecrims (em São Paulo, Minas Gerais e Rio de Janeiro) também foi de suma importância e motivada pela lei n. 10.67।/2003.

Como já mencionado, a aproximação da Justiça dos estádios de futebol deu aos assistentes uma sensação de rigor e diminuição da impunidade. Essa é uma experiência muito positiva que não deve ser abandonada até que os estádios brasileiros sejam apenas recintos de lazer e diversão. E que os espectadores dos eventos esportivos se sintam respeitados e com seus direitos fundamentais assegurados.

Esta pesquisa conclui que aproximadamente $50 \%$ dos artigos e incisos do Estatuto de Defesa do Torcedor ainda não são cumpridos, situação pela qual a Confederação Brasileira de Futebol, algumas federações afiliadas e o Poder Público são corresponsáveis.

Para o aprimoramento da lei, a pesquisa sugere ainda modificações no Estatuto de Defesa do Torcedor. Além das já apresentadas anteriormente, indica-se a inclusão de um capítulo sobre infraestrutura com as seguintes condições:

Art. $\vee$ - É direito do espectador que o estádio tenha o número de portões de acesso e de saída correspondente ao número de um para cada mil espectadores em potencial. Os setores deverão ter, no mínimo, cinco portões de acesso e saída. Cada portão de acesso deverá ter, no mínimo, cinco catracas de controle eletrônico de acesso dos espectadores, as quais deverão ser removidas para a saída dos espectadores por esses locais.

22. Expus ao longo do artigo os mais significativos para exemplificar o problema. Estes têm, segundo as minhas pesquisas, relação direta com a violência dos espectadores em dias de jogos. Em síntese, a lei apresenta 12 capítulos, 45 artigos (dois artigos foram vetados, três fazem parte das disposições gerais e quatro das disposições finais, resultando em 36 artigos que foram objetos de análise) e 47 incisos dos quais não são cumpridos 17 artigos $\left(6^{\circ}, 13,17,18,21\right.$, 22, 23, 25, 26, 27, 28, 29, 30 , $37,39,40,41$ ) e 23 incisos (sendo dois do art. $6^{\circ}$, dois do art. 14, dois do art. 17, um do art. 21 , um do art. 22, dois do art. 23, três do artigo 26, dois do art. 27, seis do art. 37, dois do art. 4I).

23. Relacionada à tragédia em 30 de janeiro de 2008 na página UOL Esporte encontra-se uma matéria intitulada: "Estádios em situação irregular recebem jogos em 2008". 
Art. W - É direito do espectador que o estádio possua no máximo cinco mil espectadores por setor. Os setores deverão ser divididos com grades de 3 metros de altura que impeçam a passagem de espectadores de um setor para o outro sem autorização.

Art. X - É direito do espectador que o estádio tenha em cada portão de entrada uma câmera instalada para o monitoramento de imagens. Assim como o mínimo de cinco câmeras de monitoramento de imagens para cada setor com, no máximo, 5 mil espectadores. No setor reservado às torcidas organizadas, deverá haver, no mínimo, oito câmeras desse tipo.

Art. Y - É direito do espectador que o estádio possua em cada setor uma lanchonete com número suficiente de funcionários para atender a demanda de consumidores.

Art. Z-É direito do espectador que o estádio tenha em cada setor banheiros suficientes para atender a demanda de usuários em condições de higiene durante todo o período de realização do espetáculo esportivo. Isso quer dizer que os sanitários deverão ser limpos antes, durante e após o intervalo do jogo.

\section{The football spectacle and the Estatuto de Defesa do Torcedor}

ABSTRACT: This article is derived from a qualitative research and its subject is the soccer spectacle in Brazil and the Estatuto de Defesa do Torcedor. The research was conducted with bibliographic approaches, documentary and field and showing the no applicability of the Estatuto de Defesa do Torcedor. This survey concludes that almost half of the articles and sections of the law n. 10.67//03 is not yet completed, a situation in which the Brazilian soccer confederation (CBF), some affiliated federations, and the Public Authorities are co-responsibles.

KEY WORDS: Football spectacle; sports legislation; Estatuto do Torcedor.

\section{El espectáculo de fútbol y el Estatuto de Defensa del Hincha}

RESUMEN: El presente artículo persigue difundir los resultados de uma investigación sobre el espectáculo futbolístico y el Estatuto de Defensa del Hincha. La investigación es conceptual, fundada en la literatura científica, y otros dados obtenidos mediante la experimentación directa e analiza las deficiencias del Estatuto de Defensa del Hincha, que dificultan su eficacia. El trabajo demuestra que casi la mitad de la ley n. 10.671/03 no se cumple por culpa, fundamentalmente, de la Confederación Brasileña del Fútbol, de algunas federaciones y de los Poderes Públicos.

PALABRAS CLAVES: Espectáculo futbolístico; legislación deportiva; Estatuto del Hincha. 


\section{REFERÊNCIAS}

BRASIL. Ministério do Esporte. Portaria n. 124 - Estabelece os requisitos mínimos a serem contemplados nos laudos técnicos previstos no Decreto n. 6.795/2009. In: SEMINÁRIO ESTÁDIOS, SEGURANÇA E CONDIÇÕES DE USO, Anais... Brasília, nov. 2009.

BRASIL. Lei n. 10.67I - Dispõe sobre o Estatuto de Defesa do Torcedor e dá outras providências. Disponível em: <http://www.presidencia.gov.br>. Acesso em: I jun 2003.

Decreto n. 6.795 - Regulamenta o art. 23 da lei n. 10.67I, de 15 de maio de 2003, que dispõe sobre o controle das condições de segurança dos estádios desportivos. Disponível em: <http://www.presidencia.gov.br>. Acesso em: 23 mar. 2009.

DUNNING, E. El fenómeno deportivo: estudios sociológicos en torno al deporte, la violencia y la civilización. Barcelona: Paidotribo, 2003.

ELIAS, N.; DUNNING, E. A busca da excitação. Lisboa: Difel, 1992.

ESCHER, T. de A. Futebol e violência: a implementação do Estatuto de Defesa do Torcedor um estudo de caso. Monografia (Licenciatura em Educação Física) - Faculdade de Educação Física, Unicamp, Campinas, 2004.

FEDERAÇÃO PAULISTA DE FUTEBOL. Resolução 37/06. Disponível em: < http:// www. futebolpaulista.com.br/federacao.php?sec $=\mid 8 \&$ sub $=\& \operatorname{cod}=\mid 40>$. Acesso em: 17 jan. 2008a.

. Resolução 35/06. Disponível em: <http://www.futebolpaulista.com.br/federacao. php? sec $=\mid 8 \&$ sub $=\& \operatorname{cod}=\mid 38>$. Acesso em: 17 jan. 2008b.

FRANCO JUNIOR, H. A dança dos deuses: futebol, sociedade, cultura. São Paulo: Companhia das Letras, 2007.

KLEIN, M. A. Preservar o espetáculo, garantindo a segurança e o direito à cidadania. Relatório final da Fase I da "Comissão Paz no Esporte". Brasília: Ministérios do Esporte e da Justiça, 2006.

LA CORTE, C. de. Estádios brasileiros de futebol: uma análise de desempenho técnico, funcional e de gestão. Tese (Doutorado em Estruturas Ambientais Urbanas) - Faculdade de Arquitetura e Urbanismo, USP, São Paulo, 2007.

REBELO, A.; TORRES, S. CBF-NIKE. São Paulo: Casa Amarela, 2001.

REIS, H. H. B. Futebol e sociedade: as manifestações da torcida. Tese (Doutorado em Educação Física) - Faculdade de Educação Física, Unicamp, Campinas, 1998.

. Os espectadores de futebol e a problemática da violência relacionada à organização do espetáculo futebolístico. Revista Paulista de Educação Física, São Paulo, v. I7, n. 2 , p. 85-92, jul./dez. 2003. 
. Futebol e violência. Campinas: Autores Associados, 2006.

. Cronologia das mortes no futebol brasileiro. Campinas: Unicamp, 2009. Mimeo-

grafado.

SILVA, S. R. da et. al. O Estatuto de Defesa do Torcedor e a questão da violência: uma análise sobre a apreciação do lazer a partir dos torcedores de futebol. Recife: Conbrace, 2007a. . et. al. Observatório do torcedor: a relação dos torcedores de futebol e torcedores de voleibol com o Estatuto de Defesa do Torcedor em Belo Horizonte. Recife: Conbrace, $2007 b$.

VASCONCELLOS, P. L. R. C. Carta de um jovem, e revoltado, torcedor do Flu. Disponível em: < http://blogdojuca.blog.uol.com.br/arch2008-06-22_2008-06-28.html>. Acesso em: 22 jun. 2008.

Recebido: 21 dez. 2008 Aprovado: 2 dez. 2009

Endereço para correspondência R. Érico Veríssimo, 709, Cidade Universitária Zeferino Vaz Faculdade de Educação Física, Unicamp

Campinas-SP CEP | 3083-85 | 